eISSN: $2387-1555$

DOI: http://dx.doi.org/10.14201/rea201987392

\title{
EL INDÍGENA CONTINÚA CON SU IDEOLOGÍA EN EL ARTE PLUMARIO DE LA NUEVA ESPAÑA. PRESERVACIÓN DEL ARTE PLUMARIO COMO FORMA DE RESISTENCIA POPULAR E INDÍGENA
}

The Indian continues with his ideology in the feather art of the New Spain. Preservation of feather art as a form of popular and indigenous resistance

O indígeno continua com sua ideologia na arte da Nova Espanha. Preservação da arte da pena como forma de resistência popular e indígena

\author{
Erika Adriana CORONA VELÁZQUEZ \\ Universidad Laval Quebec, Canadá \\ \erika.corona68@gmail.com \\ Dafne Angélica CORONA VELÁZQUEZ \\ Escuela Nacional de Antropología e Historia (ENAH) México \\ $\bowtie$ dafnecorona@gmail.com
}

Fecha de recepción: 20 de junio de 2019

Fecha de aceptación: 06 de julio de 2019

\begin{abstract}
Resumen: Con los cambios económicos, políticos y sociales durante la época colonial en la Nueva España, el indígena se introduce a un sistema de esclavitud, explotación económica y social por parte del español, quien controlaba la producción en base al mercantilismo, a la demanda de consumo, a las nuevas ideologías introducidas y al control de un nuevo modo de producción. En este momento se ampliaron nuevos oficios en la Nueva España, con ello el indígena aprendió a elaborar una nueva producción, técnicas y estilos diferentes, pero continuó con su ideología en la producción de ciertos objetos como: cerámica, figurillas sonaja, pinturas en las iglesias, cristos de caña, cristos de capullos de mariposa, etc., que reflejaban a estas dos culturas y la aculturación y europeización que se estaba generando. En la época prehispánica los indígenas relacionaban las plumas con sus dioses, con las guerras, el comercio y el tributo. Los objetos de plumas los utilizaban las mujeres de cierto rango social en los huipiles, los gobernantes y los militares en su atuendo y en sus fiestas. Las plumas eran consideradas para la sociedad como un objeto de posición social, ideológica y política. La distribución de plumas por parte del comercio abarcaba desde el área norte de México hasta llegar a Tenochtitlán. En la época colonial se dio un cambio ya que se elaboraba el arte plumario para representar a imágenes religiosas católicas como: Cristo, la Virgen María y los Santos. No era el mismo significado para estas dos sociedades; para los indígenas el uso de las plumas estaba vinculado con los dioses y formas de conducta establecidas en la época prehispánica, mientras que para los españoles lo relacionaban con la religión católica y con su propia ideología. Para la sociedad indígena dominada, el uso de la pluma continuó con su significado cultural y se volvió parte fundamental de sus códigos de comunicación. En este sentido el uso de la pluma en los cuadros y la vestimenta se convirtió en una forma de resistencia cultural contra la imposición social dada en la colonia.
\end{abstract}

Palabras clave: arte plumario; códigos culturales; amanteca; rango social; resistencia.

\begin{abstract}
With the economic, political and social changes during the colonial period in New Spain, the indigenous population was introduced to a system of slavery, economic and social exploitation by the Spanish, who controlled production based on mercantilism, consumer demand, to the new ideologies introduced and to the control of a new mode of production. At this time new trades were expanded in New Spain, with this the Indian learned to develop a new production, techniques and different styles, but continued with his ideology in the production of certain objects such as: ceramics, rattle figures, paintings in the churches, christs of cane, christs of butterfly buds, etc., that reflected these two cultures and the acculturation and Europeanization that was being generated. In pre-Hispanic times the Indians related feathers with their gods, with wars, in commerce and tribute. Feather objects were used by women of a certain social rank in the huipiles, the rulers and the military in their attire and in their parties. The pens were considered for society as a luxury object. The distribution of feathers by the trade ranged from the northern area of Mexico to Tenochtitlán. For the dominated indigenous society, the use of the pen continued with its cultural significance and became a fundamental part of its communication codes. In this sense the use of the pen in the paintings and clothing became a form of cultural resistance against the social imposition given in the colony. In colonial times there was a change since feather art was elaborated to represent Catholic religious images such as: Christs, the Virgin Mary and
\end{abstract}


the Saints. It was not the same meaning for these two societies, for the Indians the use of feathers was linked to the gods while the Spaniards related it to the Catholic religion and to their own ideology.

Keywords: feather art; cultural codes; amanteca; social rank; resistance.

Resumo: Com as mudanças econômicas, políticas e sociais durante a era colonial na Nova Espanha, indígena a um sistema de escravidão, exploração econômica e social é introduzido pelos espanhóis, que controlava a produção com base no mercantilismo, a demanda do consumidor, às novas ideologias introduzidas e ao controle de um novo modo de produção. cerâmica, estatuetas sonaja, pinturas nas igrejas: Neste momento novos escritórios em Nova Espanha, assim indígenas aprenderam a desenvolver novas técnicas de produção e estilos diferentes, mas continuou sua ideologia na produção de determinados itens, como expandida , cristos cana, cristos de casulos de borboleta, etc., que reflectem estas duas culturas e acculturation e europeização que foi gerado.Nos tempos pré-hispânicos, os índios relacionavam penas com seus deuses, com guerras, comércio e tributo. Objetos de penas usado deles mulheres de uma certa posição social na huipil, os governantes e os militares em seus trajes e seus partidos. As canetas foram consideradas pela sociedade como um objeto de luxo. A distribuição de penas pelo comércio variou da zona norte do México a Tenochtitlán.Nos tempos coloniais, houve uma mudança, uma vez que a arte das penas foi elaborada para representar imagens religiosas católicas como: cristos, a virgem Maria e os santos. Não era o mesmo significado para estas duas sociedades, para uso indígena de penas estava ligada aos deuses enquanto os espanhóis relacionados com a religião católica e sua própria ideologia. Para a sociedade indígena dominada, o uso da caneta continuou com seu significado cultural e tornou-se parte fundamental de seus códigos de comunicação. Nesse sentido, o uso da caneta nas pinturas e roupas tornou-se uma forma de resistência cultural contra a imposição social dada na colônia.

Palavras-chave: arte de penas; códigos culturais; amanteca; posição social; resistência.

\section{Introducción}

Este trabajo pretende entender el papel que desempeñaba el arte plumario para la sociedad azteca, antes y después de la imposición española, conocer la importancia y el uso de las diversas aves que conforman distintas áreas de México, además de analizar el conocimiento que tiene la sociedad mesoamericana acerca de las aves y su relación con su cosmovisión. En la época prehispánica se generó un modo de producción establecido a través del tributo, una organización social determinada a través de una estratificación social, una propiedad de la tierra de forma comunal y privada, un estado militarista y un comercio especializado. Dentro de este contexto uno de los elementos que servían para la comunicación de esta forma de producción eran los símbolos que se transmitían a partir de un lenguaje pictográfico. Uno de los artistas más importantes de esta época era el amanteca ${ }^{1}$, el realizador del arte plumario.

En la época prehispánica se dio un conocimiento del arte plumario creado por los amantecas que empleaban distintas técnicas para la elaboración de diversos objetos como tocados, huipiles, chimalis, mosaicos, etc. Las aves que utilizaban estos artistas de la pluma eran muy diversas y entre ellas destacaban: las garzas, la guacamaya roja, los pericos, el trogón mexicano, el troupial, la garza espátula rosada, los patos, los colibríes, el cotinga azuleja, el zanate, el pájaro zacuan y el quetzal².Los amantecas en la época prehispánica generaron una especialización en el uso de plumas, una distinción de diversas técnicas empleadas en las elaboraciones de artículos de rango, guerra y suntuarios. La importancia de las aves se da a partir de su valor ideológico y de su relación como producto de su medio ambiente, del comercio, del tributo y de la relación con sus dioses. En suma, la plumaria era una de las artes más finas y delicadas del México prehispánico (FILLOY NADAL, SOLÍS OLGUÍN Y NAVARIJO 2007: 85).

Debido a la importancia de los calpullis $^{3}$ dedicados al mantenimiento del imperio azteca, la sociedad realizó tareas productivas en el campo y especializaciones, tareas como la cerámica, la cestería, la confección

\footnotetext{
${ }^{1}$ Un grupo de especialistas, conocido en lengua náhuatl bajo el nombre de amanteca, tenían a su cargo la elaboración de toda suerte de escudos, trajes, tocados, brazaletes, ajorcas, banderas, capas y abanicos con plumas multicolores. Estos bellos objetos tenían una enorme importancia entre los aztecas, pues servían para exaltar la jerarquía de dioses, reyes, señores, sacerdotes y guerreros. Véase Filloy Nadal, Solís Olguín y Navarijo (2007: 85).

${ }^{2}$ Quetzal cuyo nombre del náhuatl quetzalli que quiere decir hermosa pluma dato sacado de la Real Academia Española.

${ }^{3}$ El calpulli era una célula social fundamental del pueblo mexica y basada en el parentesco. Tenía su propio jefe electo que duraba en su cargo hasta que era útil, esto es, podía haber alguna razón para relevarlo; podía ser destituido. Se sabe que hubo 20 grupos consanguíneos o calpullis divididos en cuatro barrios, lo cual supone la existencia de las fratrías propias de los pueblos comunitarios, y los barrios formaban, a su vez, el conjunto del pueblo azteca. Véase Hernández Vaca (2005: 122).
} 
de objetos de piel, la elaboración de navajas y puntas de obsidiana, el arte plumario, la orfebrería, el trabajo de piedras finas, la manufactura de petates, la decoración de mantas de petates, la decoración de mantas y la carpintería. Para Florescano (1983: 90-100), en la época colonial, con el control jurídico, político y económico, los españoles cambiaron el sistema de producción indígena en el territorio, destruyendo y utilizando la administración política central que antes asignaba y la organización de la tierra, el trabajo y la redistribución de los bienes que sostenían su producción. Según este autor, los indígenas en la época colonial ya no tenían control de su tierra, sino que ahora se les designaba su papel en ella con el surgimiento de las encomiendas las unidades productivas de cada aldea, barrio, territorio, perdieron su vinculación con el sistema central que las unificaba y reproducía globalmente, quedando desarticuladas sin sus centros políticos, sometiéndose a las demandas e intereses del encomendero que les había tocado. En su obra «Los gremios en la Nueva España» presentado por De la Torre Villar (1998), Manuel Carrera Stampa comentó que los artesanos en la época colonial trabajaron libremente sobre todo en el siglo XVI y parte del XVII, el artesano o maestro poseedor de un taller vendía directamente al consumidor. Sin embargo, precisó este autor, el control de la producción y de los productos manufacturados en los gremios fue pasando gradualmente en manos de comerciantes, quienes acaparaban las manufacturas y verificaban el precio de los artículos obteniendo ganancias en su distribución y ventas (De la Torre Villar 1998: 320). Es importante resaltar que este trabajo, aparte de destacar la importancia que generaron los amantecas productores del arte plumario, en la época prehispánica y colonial, menciona la supervivencia de algunas de las técnicas y objetos realizados como los huipiles, que se continuaron elaborando con códigos pictográficos y plumas de la sociedad indígena y su comunicación social.

\section{La utilización de las aves en la época prehispánica}

Es importante señalar que las sociedades mesoamericanas tienen una visión cultural que va a conectar a la naturaleza con su propia realidad. Los dioses mesoamericanos se relacionan con el cosmos, con la naturaleza y con la sociedad en este entendimiento, todos los seres vivos conectan con su forma de vida y tienen relación con los dioses. Hay un vínculo con el mundo celestial, el inframundo y los niveles del cosmos: son los animales que representan estos niveles cósmicos. A su vez, los dioses creadores, al establecer diferencias entre los dioses que viven en los cielos, los que moran en los diferentes niveles del inframundo, o los que habitan en los cuatro rumbos del cosmos, van definiendo una jerarquía de las divinidades.

En estos casos la jerarquía divina está relacionada con las actividades y el espacio humanos, y por eso repite el modelo de la organización social, o los distintos ámbitos del mundo terrestre, que, en los mitos cosmogónicos y teogonías, corresponden a los espacios habitados por las potencias encargadas de favorecer los bienes de los que dependía el desarrollo humano (FLORESCANO 1997: 53). Uno de los grupos de animales que tienen una relación directa con los dioses son las aves, ya que representan un vínculo directo entre su cosmogonía y la realidad. Como lo analizan Rivero Weber y Feest: «La leyenda narra que Quetzalcóatl enseñó en Tula las artes mecánicas de fundir la plata, labrar la piedra y la madera, pintar y hacer plumajes» (RIVERO WEBER Y FEEST 2012: 41). Así que la pluma forma una parte fundamental del lenguaje pictográfico que va a enseñar a las sociedades a entender la expresión de los dioses y el comportamiento de la sociedad. Al mismo tiempo tiene un papel esencial en la economía de las sociedades mesoamericanas. Hay que entender el uso de la pluma a través de su carga simbólica pues sus colores representaban las figuras de los dioses a los que se veneraba. A nivel de las relaciones de producción, la pluma tiene un papel preponderante no solo como 
objeto de tributo de las sociedades dominadas sino que también es uno de los elementos de prestigio que forma parte fundamental de la economía de la región. Según Vaillant (1965:181), los aztecas asociaban a las aves con sus dioses y diosas. En relación a esto se puede observar en el códice Borbónico cómo se representan a las trece aves agoreras que acompañan a los señores del día.

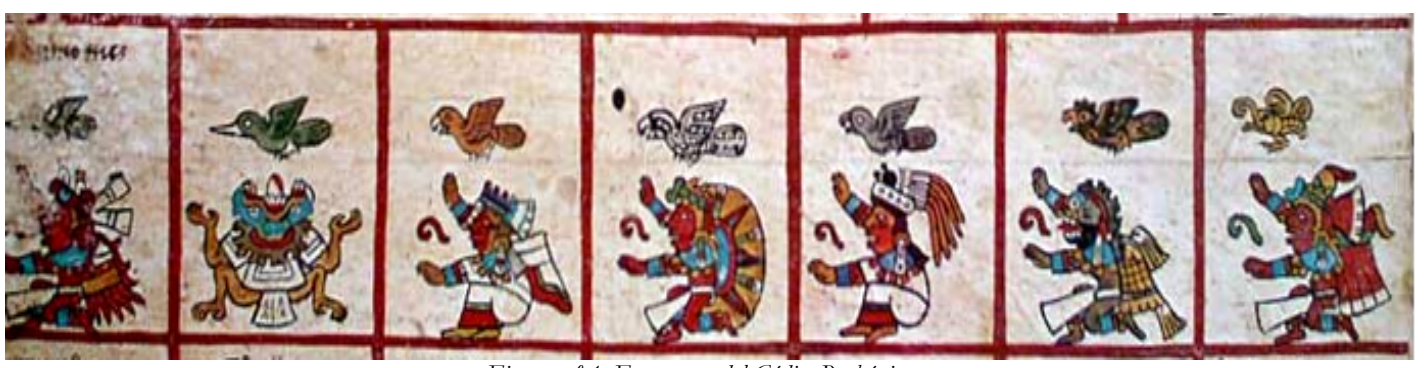

Figura n. ${ }^{\circ}$. Fragmento del Códice Borbónico

En el siguiente cuadro podemos observar la asociación entre los dioses, la identidad con la naturaleza y el tipo de ave.

\begin{tabular}{|l|l|l|}
\hline Dios & Identidad con la naturaleza & Ave (nahual) \\
\hline Xiuhtecutli, & Dios del fuego & Colibrí Blanco \\
\hline Tlaltecuhtli & Señor de la Tierra, el monstruo de la tierra, & Colibrí Verde. \\
\hline Chalchihutlicue & Dios del agua & Halcón \\
\hline Tonatiuh & El sol, dios solar & Colibrí \\
\hline Tlazolteotl & Madre de la tierra & Águila \\
\hline Teoyoamiqui & Guerrero muerto, dios muerto & Lechuza aulladora \\
\hline Xochipili & Príncipe de las flores & Mariposa \\
\hline Tláloc & Dios de la Lluvia & Águila Lisada. \\
\hline Quetzalcóatl-Ehecatl & Dios de la Sabiduría & Guajolote \\
\hline Tezcatlipoca & Gran Dios & Lechuza de cuernos \\
\hline Mictlantecuhtli & Dios de la Muerte & Guacamaya \\
\hline Tlahuizcalpantecuhtli & Señor de la caza de la Aurora, Dios Venus, variante de & Quetzal \\
\hline Quetzalcóatl & Loro \\
\hline Ilamatecuhtli & La Vieja princesa, antigua Diosa de la Tierra & \\
\hline
\end{tabular}

Dentro de este contexto la pregunta es ¿Cuál es la importancia que tienen las aves para las sociedades mesoamericanas? Desde la época preclásica el ave se comercializaba en distintas áreas. Tal es el caso de las guacamayas (ara macao). Estas aves son de origen tropical y aparecen entre la cultura olmeca y la cultura zapoteca en Monte Albán. Según Romero Blanco y Méndez (2017: 163), para la época del periodo clásico se continuaba comercializando las aves, pero para los mayas las aves las consideraban como animales con gran capacidad, de estar en la tierra, en el agua y el cielo. Esto los convirtió en seres idóneos para ayudar a los hombres a establecer contacto con las deidades, tanto celestes como del inframundo. Al pájaro principal 
conocido como el quetzal simbolizaba el nivel celeste del universo maya y reside sobre el árbol del mundo. Las plumas de esta ave se portaban en tocado y orejeras y se representaban con ojos y colmillos de serpientes.

En la cosmovisión maya, los patos eran considerados como el alma de los difuntos y mensajeros de las nubes hacia las diferentes direcciones del mundo sagrado. También se le consideraba portadores de las semillas en los ritos agrícolas de fertilidad. En cambio, el zopilote rey (Sarcoramphus papa) y el zopilote negro (coragyps atratus) encarnaban las energías sagradas de la muerte provenientes del cielo y del inframundo. Navarijo Ornelas relata que para los mayas la guacamaya roja (ara macao) era considerada como encarnación del fuego solar, por desplegarse desde el cielo hasta la tierra, también se puede vincular con el color rojo escarlata del plumaje y el hecho de que en la distribución del mundo el rojo era el color asignado al punto cardinal del este, siendo el oriente por donde nace el sol (Navarijo Ornelas 2000: 24). Según esta autora, esta sencilla asociación nos proporciona las bases que justifican el nombre de Guacamaya-de-Ardiente-RostroSolar (Navarijo Ornelas 2000: 24).

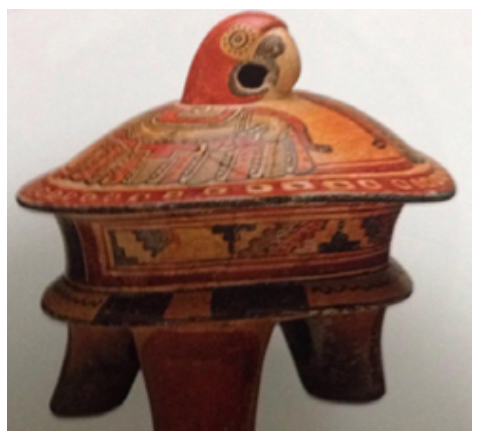

Figura n. ${ }^{\circ}$. Tapa con cabeza de Guacamaya Becan, Campeche, época Clásico Temprano, Fuente: Museo Nacional de Antropología e Historia. Romero Blanco y Méndez. (2017)

Para los teotihuacanos, que representaban aves del valle de México en la pintura mural, ciertas aves estaban relacionadas con el sol. En la pintura mural de Tetitla, lugar donde residían los sacerdotes, se encuentran representaciones de águilas con gotas de sangre en el pico que se relacionan con el sacrificio. A partir del mural de Tetitla, Navarijo Ornelas propone en esta interpretación: al águila se le relaciona con el sol dador de vida, ese sol que recorre su camino del alba al ocaso en un morir y renacer eternos, simbolizado por el poderoso vuelo del águila, a decir de una significación de vida-ascendente y de muerte-descendente (NAVARIJO ORNELAS 2000: 19). La importancia de las plumas era que también los sacerdotes la utilizaban como parte de su vestimenta portando tocados con colibrí.

Para los aztecas la hermosa ave guacamaya, era considerada como un nahual de sol y para las culturas del norte como Paquimé, la guacamaya se convirtió en un elemento simbólico muy importante, fueron utilizadas como un elemento ideológico fundamental, adaptando su imagen a todo tipo de diseños, algunos muy sofisticados, otros simplificados o estilizados, entre otros el de un «hombre guacamaya» al cual se le agregó sobre el vientre el símbolo del maíz: el pequeño cuadro con un punto central (BRANIFF CORNEJO 2009: 34).

El quetzal fue considerado un ave importante para los aztecas, ya que elaboraron objetos como el penacho de Moctezuma, relacionado con Quetzalcoatl. Para elaborarlo utilizaron los amantecas plumas verdes de quetzal adornado con piedras preciosas doradas y pequeñas plumas de color rojas, azul turquesa y pardas. Aparte de este objeto de rango usado por el tlatoani, realizaron abanicos con estructura de caña con 
motivo central de una bella mariposa, escudos emplumados resaltados en lámina de oro. (FILLOY NADAL, SOLÍS OLGUIN, Y NAVARIJO, 2007: 86).

La elaboración del arte plumario por los aztecas se expandió durante el periodo de Ahuízotl (14861502) (MUÑOZ 2006: 123). Con la consolidación de la hegemonía de la Triple Alianza, se dio un fortalecimiento de grandes redes de tributo que posibilitó el acceso a plumas provenientes de diferentes tipos de ambientes diferentes, sumándose a las redes tributarias, las redes comerciales encabezadas por los pochtecas también se intensificaron dando acceso a plumas con una variedad de colores incomparables a las que se consiguen en la actualidad (ESTRADA DE GERLERO 1994: 75). Debido a ello las plumas se presentan como un marcador social y elemento religiosos ligado a la expansión mexica (MUÑOZ 2006: 123).

Las aves que utilizaban los amantecas provenían de ecosistemas diferentes al de Tenochtitlán, estas llegaban como mercancías o como tributo, el 34\% de las Provincias ubicadas en las zonas tropicales del sur y de la costa del Golfo enviaban plumas a la Capital (FILLOY NADAL, SOLÍS OLGUÍN Y NAVARIJO 2007: 94). El comercio de aves a través de redes comerciales se dio entre mesoamérica, el occidente, la gran chichimeca y el noroeste de México (BRANIFF CORNEJO 2009: 27). Los amantecas utilizaban dos tipos de aves: las cautivas que estaban destinadas para la contemplación del rey y su corte y las aves de tributo que eran las águilas, guacamayas y pericos, procedentes de seis provincias ubicadas en la costa del Golfo, Oaxaca y el estado de Hidalgo. De las aves de tributo que utilizan los amantecas, Filloy Nadal, Solís Olguín y Navarijo (2007: 94) mencionan que los amantecas utilizaron diversas aves de distintas provincias tributarias, para el color amarillo utilizaron las aves Cacicas melanicterus o caxcaxtótotl, pájaro zacuan, procedentes de las tierras bajas del Pacifico de Sonora hasta Chiapas, para el color azul intenso Cotinga amabilis o xiubtótotl (cotinga azuleja) provenientes de en las tierras bajas del Golfo, el sur de Veracruz, el norte de Oaxaca, el norte de Chiapas y Centro América, para el color café blanquesino utilizaron el ave Anas acuta (pato golondrina) de la cuenca de México, para el color rojo utilizaron las plumas caudales de Ara macao de guacamaya roja (alo, en náhuatl) provenientes del sur de Tamaulipas, Tabasco, Oaxaca, Chiapas y Campeche.

\section{El papel del amanteca y el impacto social e ideológico de su arte en la época prehispánica}

El arte plumario fue realizado desde la época prehispánica por los amantecas o amantecatl, el artista de las plumas que «hace trabajos de pluma, las escoge, las ordena, las pinta de diversos colores, las junta una con otras» (LÉON-PORTILLA 2006: 266). El comentario de Filloy Nadal, Solís Olguín y Navarijo (2007: 88) acerca del libro IX del Códice florentino de Sahagún permite entender los dos tipos de amantecas: los calla y los tecpan. Por un lado, se encontraban los calla amanteca, quienes residían en el barrio de Amatlan y vendían sus productos en el circuito mercantil. Por el otro, tenemos a los tecpan amanteca, habitantes del palacio real que estaban consagrados al servicio del soberano. Al parecer, los primeros se hacían de la mayor parte de sus materias primas en los mercados de la ciudad, en tanto que los segundos las obtenían en las arcas reales, alimentadas por los tributos y regalos de todo el imperio.

Como lo precisan los autores Filloy Nadal, Solís Olguín y Navarijo (2007: 96), estos últimos contaban con un sitio privilegiado para trabajar, la Casa de las Aves de Moctezuma que formaba parte del complejo palaciego. El trabajo de arte plumario lo realizaban los aztecas, pero anterior a este grupo lo hacían los toltecas. Como lo precisa León Portilla (74-75) en la parte intitulada «Corazón endiosado que enseña a mentir a las cosas»: 
«Toltecayotl o conjunto de las creaciones toltecas, lo atribuian los nabuas a Quetzalcóatl. Él había construido sus palacios maravillosos, orientados hacia los cuatro rumbos del universo en la metrópoli tolteca en la metrópoli tolteca. Alli habia descubierto para beneficio de su pueblo los metales y las piedras preciosas, el cultivo de algodón y de otras muchas plantas de valor inapreciable. Él les habia enseñado sus variadas artes: desde la técnica de cultivar con el mayor rendimiento la tierra y de encontrar los metales preciosos, hasta las formas de trabajarlos, de hacer tapices y penachos con plumajes de colores, el arte del canto, de la pintura, la escultura y la arquitectura.»

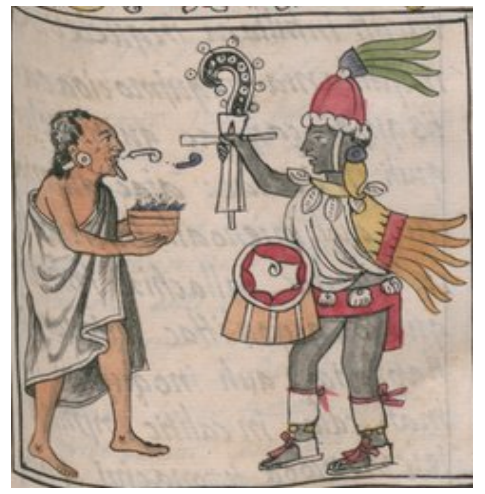

Figura n. 4. Quetzalcóatl, Códice Florentino. Libro III, folio 12

Para los toltecas Quetzalcoatl fue el dios que les enseño el oficio de las plumas, pero para los aztecas fue el dios Macuitochtli acompañado por dos mujeres Xiuhtlati y Xilo, quienes portaban las plumas de distinta forma. Como lo relata Sahagún (1950: 58) en el Códice Florentino, Capítulo 18:

"Al Dios Macuitochtli lo acompaña dos mujeres, una se llamaba Xiubtlati, va ataviada con un huipil azuly la otra que llamaba Xilo, que era la menor y va vestida con un buipil colorado, teñido con grana: estas ambas tenían los buipiles sembrados de plumas ricas de todo género de ave. La orilla del huipil estaba bordada de plumas de diversas maneras». ${ }^{4}$
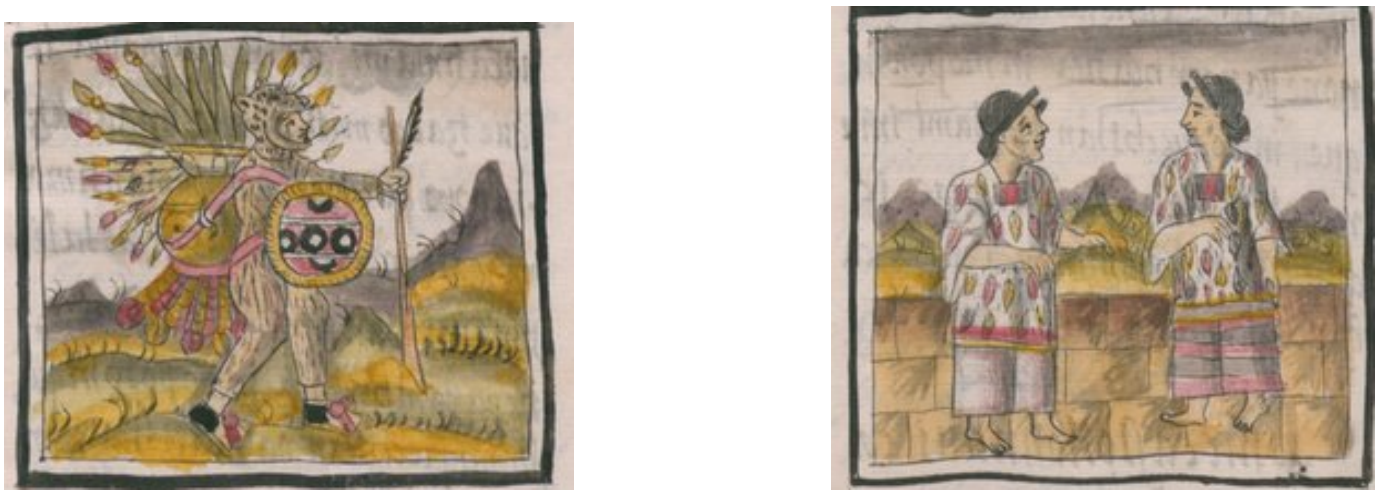

Figuras n. 5 y 6. Dios Macuitochtli con Xiubtlati y Xilo. Códice florentino Libro IX, Capitulo 18

Resulta, a su vez, muy relevante la participación de las mujeres amantecas en las fiestas del barrio amantla. Sahagún (1950: 61) menciona que los amantecas ofrecían sus hijos a los dioses, para que las mujeres desempeñaran el oficio de las plumas, los dioses las ayudaban para que fueran grandes lavanderas, buenas tintoreras de tochomitl en todos los colores para pluma.

${ }^{4}$ Fray Bernardino Sahagún, Codex, General History of the Things of New Spain (1575-1585). Libro IX, Capítulo XVII. folio. 58. 
Los objetos que se elaboraban de pluma eran objetos de lujo, para los dioses y de uso militar. Las técnicas que utilizaban los amantecas con las plumas eran diferentes ya que procedían de distintas formas, según Filloy Nadal, Solís Olguín y Navarijo (2007: 85), «los amantecas realizaban escudos, huipiles, tocados, brazaletes, ajorcas, banderas, capas y abanicos». Una en lo particular, relatada por Sahagún y resumida por Filloy Nadal, Solís Olguín y Navarijo (2007: 89), era a través del «anudado de las plumas con fibras de maguey sobre bastidores de caña o madera» para confeccionar «los abanicos, mosqueadores, brazaletes, capas, penachos, tocados e insignias». Para los mosaicos, los amantecas apoyados por los diseños de los tlacuilos, utilizaban una penca de maguey de superficie tersa, aplicaban el engrudo adhiriendo fibras de algodón sin hilar y dejaban secar, después calcaban con la ayuda de un pincel (FILLOY NADAL, SOLÍS OLGUÍN Y NAVARIJO 2007: 89).

Es importante mencionar que la elaboración de arte plumario es fruto de un entendimiento profundo del entorno sociopolítico e ideológico de la época, no solamente de las técnicas utilizadas en su creación, sino también del conocimiento del creador (llamado «amanteca») con su ideología, medio social, modo de producción y su ecosistema. Además responde a una enseñanza del oficio y a una forma de entender las relaciones sociales e ideológicas de su sociedad y de distinguir el rango y el estatus social del que porta la indumentaria. Dentro de este contexto, el significado de la pluma tiene un sentido más cosmogónico y está vinculado con los dioses prehispánicos y con la forma de entender su representación en la tierra. Tal como lo analiza Russo (1998:70):

\begin{abstract}
«Las plumas son ornamentos constantes de todos los dioses principales y de sus figuras sobre la tierra. La escultura en los bajo relieves, las pinturas, hasta llegar al emblema más dramático de la divinidad, el sacrificado (...). Durante las ceremonias que precedian los sacrificios humanos, se perpetuaba la observación de la regla que impedia ponerse ornamentos de plumas sin el permiso del tlatoani: prisioneros o esclavos sin más derechos se transformaban en la figura del dios al cual estaban por ser sacrificados y en esta identificación, tomaba sobre su cuerpo los atributos principales de la divinidad: las plumas.»
\end{abstract}

Todo tiene que ver con el conocimiento del entorno, su ecosistema, el significado de los objetos y de los colores, así como la posición social y el conocimiento de la sociedad a la que se pertenece. Hay una educación previa en donde el amanteca aprende a expresar los códigos políticos e ideológicos de la época ya que estamos hablando de una sociedad «estamentaria ${ }^{5}$ » en donde cada individuo tiene una posición en la pirámide social a la que pertenece. La cual se refleja en su vestido y sus útiles de trabajo. Como es el caso de los emperadores, los guerreros, los nobles y la clase popular ${ }^{6}$. En este sentido, el arte plumario expresa la importancia de la persona que lo portan, tanto en la indumentaria ornamentos y en sus útiles de mando o guerra. Como ejemplo, podemos ver los escudos de guerra (chimalis ${ }^{7}$ ). En su estudio sobre el arte plumario Rivero Weber y Feest (2012: 41), mencionan el gran conocimiento que estos artistas tenían de su entorno político y social:

"Cuentan los informantes indigenas de Sabagún que los toltecas era gente experimentada; se dice que eran artistas de las plumas, del arte de pegarlas. De antiguo lo guardaban; era en verdad invención de ellos el arte de los mosaicos de plumas. Por eso se les encomendaban los escudos, las insignias, las que se decían apanecáyotl. Esto era su herencia, gracias a la cual se otorgaban las insigniass.

\footnotetext{
${ }^{5}$ Según Carrasco (1975: 180), en la sociedad prehispánica, todos los indígenas constituyan una "categoría social sujeto a un régimen de derecho popular peculiar distinto".

${ }^{6}$ Es importante recalcar que los estamentos dentro de la época prehispánica sí tenían movilidad social. Véase: Carrasco (1975:180).

${ }^{7}$ Nombre dado a los escudos en la época prehispánica.
} 
Para estos autores, las plumas es un distintivo social y no cualquier grupo podía usar cualquier pluma. Al mismo tiempo, el trabajo que realizaban los amantecas obedecía a un gran conocimiento de las relaciones sociales y económicas de su entorno, de las técnicas de elaboración del producto y al uso de su ecosistema, así como el plasmar el rango y la importancia política de los individuos que lo portaban. Navarijo Ornelas (1998) analiza el relato del dominico fray Diego Durán sobre el uso restringido de las plumas. Para Durán el linaje en la época prehispánica, constituye «una prueba sobre un sistema de distinción y personalización como un producto de las necesidades socioeconómicas que imperaban en el mundo prehispánico» (NAVARIJO ORNELAS 1998: 179). Para la autora, el arte plumario refleja un conocimiento completo tanto del producto como de la sociedad en la que se vivía. En este sentido el amanteca no solo expresa su realidad, sino utiliza la pluma como parte fundamental de la expresión de los códigos ideológicos de la época. El creador de este arte estudia las técnicas, se prepara y expresa la importancia de la cultura, la divinidad y del individuo a través de la belleza de la pluma. Además, comunica a la sociedad la jerarquía que existe, la cual se refleja en la indumentaria y en los ornamentos que se portan.

Para autoras como Olko (2006), las expresiones de arte que creaban los amantecas tenían que ver con un complejo lenguaje de códigos que observaban las leyes suntuarias del mundo azteca: «Del mismo modo, la joyería y adornos de plumas preciosas se restringían a los soberanos, incluyendo a los de las provincias conquistadas, y a los restringían a los soberanos, incluyendo a los de las provincias conquistadas, y a los grandes señores» (OLKO 2006: 64). La autora analiza la importancia de las leyes suntuarias en donde había ciertas indumentarias y ornamentos que eran usados por gobernantes, nobles y guerreros de alto rango. El uso de estos accesorios estaba prohibido para la sociedad civil. La pluma es uno de los elementos suntuarios que refleja, a partir del lenguaje pictográfico, códigos de comunicación ideológicos que son parte de la expresión política y social de esa época, ya que expresa no solo los rangos sino las relaciones de poder del mundo prehispánico que iban desde la representación de los dioses hasta la diferenciación de los Tlatoanis ${ }^{8}$. El mundo prehispánico no se puede entender sin el código de la pluma.

\section{Importancia del arte plumario y distinción social en la colonia}

En la época colonial se da un periodo de adaptación en donde la transformación implica la aceptación de un nuevo régimen sociopolítico, en el cual el rol de la iglesia es fundamental para la imposición de esta nueva forma de entender las relaciones sociales y de poder. Como lo analiza Carrasco (1975: 179): «La transformación fundamental de la sociedad indígena consistió en la supresión de las instituciones políticas mayores, la disminución del tamaño e importancia de la nobleza, la posición de ésta al servicio de los conquistadores, la conservación de la masa campesina y la cristianización forzada como medio de dominio ideológico». Hay, como se ve, cambios y transformaciones en todas las instituciones y grupos sociales. La colonia refleja un sometimiento en todos los sentidos. Siguiendo el estudio de Carrasco (1975), es el grupo noble indígena él que tiene un papel fundamental en esta transformación social. Este grupo cumple una doble función en este cambio. Para este autor: «La nobleza indígena fue el vehículo para la conservación de algunos de los elementos de la cultura prehispánica, como las tradiciones históricas y durante algún tiempo, artesanías

${ }^{8} \mathrm{Al}$ respeto de la presencia de altos funcionarios de la organización prehispánica que persistía durante los primeros años Carrasco (1975: 185) precisa: "con el señor o tlatoani gobernaba el tlacochcalcatl teuctli o gobernador, el tlacatecatl, capitán general, el cuaubnochtli o alguacil mayor y otros funcionarios, todos ellos con las mismas funciones que en la organización antigua". 
de lujo» (CARRASCO 1975: 180). Pero al mismo tiempo este grupo social acepta y se adapta a la cultura española, pues era el grupo que más privilegios tenía.

Siguiendo esta lógica no solo los grupos artísticos servían a los grupos de poder como a la iglesia y a la corona, también respondían a las necesidades de la nobleza indígena que todavía tenía los beneficios de la corona durante toda la época colonial a partir de títulos políticos y tierras. Siguiendo el análisis de Carrasco, es a través de los grupos nobles el modo como se sostiene el dominio de las instituciones españolas pues son estos grupos los reconocidos por la sociedad dominada.

Una de las actividades artísticas que se adaptaron y sobrevivieron en esta época fue el arte plumario. Los creadores de esta forma de expresión ideológica continuaron con el oficio del trabajo de la pluma aunque el cambio fue evidente.

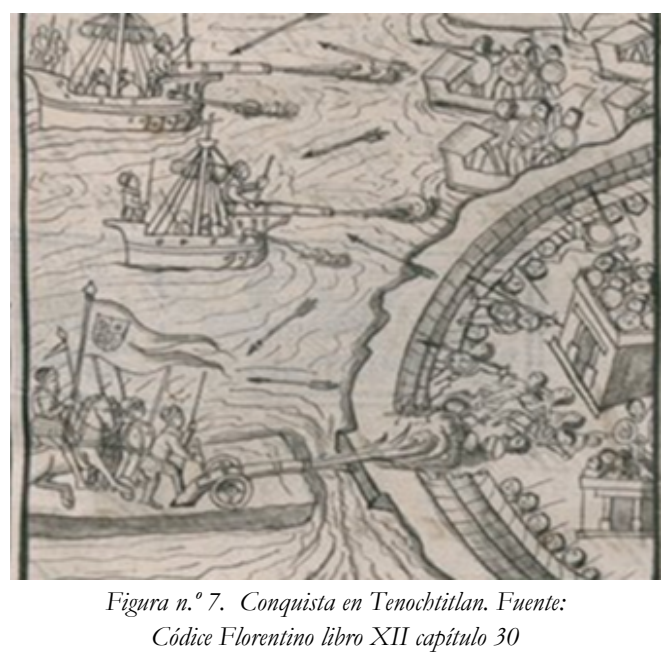

Como lo habíamos señalado, en la época prehispánica, los amantecas junto con otros grupos artísticos eran los encargados de distinguir los rangos sociales y de mostrarlos a partir de diversas técnicas de trabajo de pluma para la elaboración de indumentarias, ornamentos y útiles de mando o guerra.

El amanteca cumplía una función, la de expresar el reflejo social y político de la época. Como otros grupos artísticos, se encargaba de distinguir los diversos rangos políticos como militares de los estratos nobles y populares de la sociedad prehispánica. Como lo analiza Muñoz (2006: 131) basándose en la noción de conocimientos implícitos de Mary Douglas: «La lectura indígena de las imágenes estaba codificada, llevaba consigo unos implícitos y era tanto una expresión de una estructura, como una modificación de ella. Por medio de la expresión pictográfica los náhuas se relacionaban con un orden político, se situaban dentro de él, y lo alteraban».

En la época colonial el trabajo que realizaba el amanteca era importante, ya que el cambio fue evidente y su conocimiento se utilizó para la creación de obras de arte religiosas reconocidas en Europa. Pues es la iglesia católica la que tiene en esta época el control ideológico de la colonia y utiliza entre otros grupos el conocimiento de los amantecas para dar fuerza a las imágenes religiosas y a la nueva cultura en el poder. Aquí, la pregunta es: ¿qué es lo que expresa el arte plumario en esta época? Las imágenes cambian, pero los códigos siguen expresando su ideología, la cual se refleja tanto en los retablos como en todo lo que ellos elaboraban, como lo explica Muñoz (2006: 133) utilizando a Certeau en su análisis: «El arte plumario debe adecuarse a una

\footnotetext{
${ }^{9}$ Muñoz (2006: 131) precisa al respeto: «la manera en la que se conoce el mundo está determinada por unos conocimientos implícitos que son producto y producen unas relaciones sociales. La percepción es estructurada por la posición que se tiene dentro de unas convenciones culturales y, a su vez, sostiene y cuestiona unos órdenes sociales»
} 
simbología europea; no queriendo decir esto que pierda sus otras significaciones». Por la importancia de este grupo, la iglesia lo utiliza para expresar la ideología católica a la sociedad indígena dominada y utilizar los elementos prehispánicos en el arte religioso. De una forma la iglesia utiliza los elementos iconográficos para reeducar a la sociedad indígena. Sin embargo para el amanteca su arte servía para expresar la ideología mesoamericana y plasmar estas ideas en la iconografía colonial y con esto seguir expresando elementos de su propia cultura e identificarlos con la sociedad. Así, el arte del amanteca refleja el vínculo de la cosmogonía prehispánica y el mundo religioso católico.

\title{
V. El saber hacer: lenguaje social del arte plumario en la época colonial
}

Según Léon-Portilla (1988), los conquistadores admiraron de las culturas de México las pirámides, los monumentos, sus esculturas y pinturas, sus ricos trabajos en oro, plumas y jades. Cortés y Carlos V refiere a estos objetos maravillosos. Para León Portilla (1988: 156):

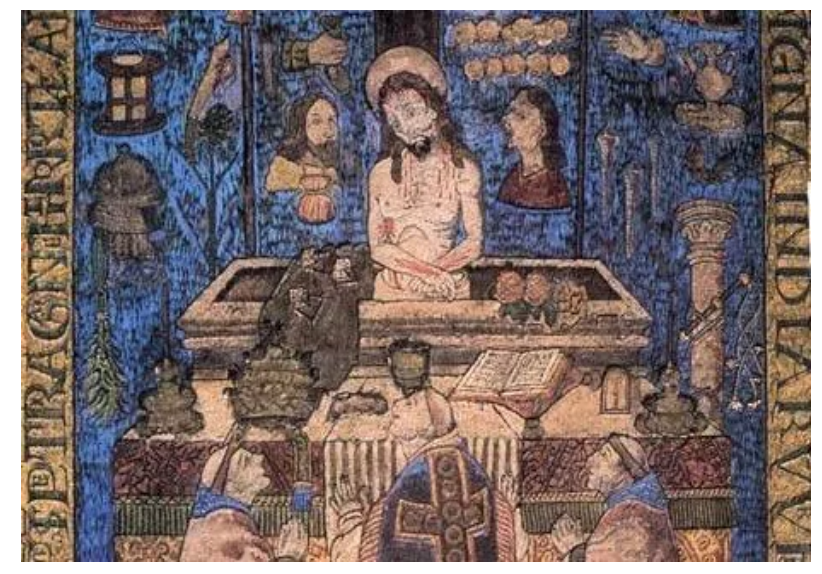

Figura n. ${ }^{\circ}$. Misa de San Gregorio Fuente: Reflexiones alternas

\begin{abstract}
«Estas referencias de los conquistadores, sobre estas categorías estéticas de tipo occidental de las producciones del mundo nábuatl, muchas aparecen a sus ojos como objetos bellos, artísticos, otras en cambio le resultan incomprensibles y no encuentran palabras para describirlas y clasificarlas. Los objetos que guardaban alguna analogía con creaciones artística de tipo occidental recibian el calificativo de bellas y genuinas obras de arte. En cambio, otras como por ejemplo Coyolxaubqui, Xolotl y Coatlicue parecian incomprensibles y, a sus ojos monstruosas».
\end{abstract}

En este sentido, para Muñoz (2006: 122): «Estas miradas asumen que la representación de motivos europeos por medio de la plumaria se convirtió en un espacio de 'aculturación' en donde los significados de la pluma se perdieron, para volverse simplemente contenedores de los mensajes iconográficos europeos».

En cambio, para Russo (1998: 64):

«Los mosaicos de las Indias como fueron llamadas y apreciadas en Europa las obras de los hábiles amantecas mexicanos, se transformaron rápidamente en simbolos de una catequización en pleno desarrollo, objetos de curiosidad, pero sobre todo fueron obras maestras que dejaron testimonio no sólo de virtuosismo con un material muy insólito para la mentalidad europea sino de sensibilidad por los colores y singularidad en la forma, dentro de figuras que dejan entrever un encuentro.»

Si bien las imágenes eran producidas para la iglesia y para la corona, dentro de la iconografía religiosa se expresaban códigos culturales dirigidos a la sociedad indígena, la cual luchaba por proteger su identidad. El uso de la pluma, la expresión de los colores, el tipo de aves, las técnicas utilizadas, los dibujos, eran parte de 
un significado ideológico propio de la sociedad prehispánica, los cuales tenían el mismo significado que en la época Mesoamericana y eran fruto de una cosmovisión que reflejaba una organización política y económica del trabajo, la cual tenía un impacto en la ideología y el espacio social. La cosmovisión indígena y su reflejo político e ideológico se expresaron en los cristos y las vírgenes. Los códigos ideológicos quedaron reflejados en bellos cuadros, imágenes y relieves religiosos.

Como hemos observado en la época colonial, el arte plumario cambia, así como su entorno social, económico y ecológico. Los valores se transformaron y la pluma deja de tener eses sentido de divinidad, pero solo para las instituciones políticas e ideológicas de la época, no para los grupos indígenas dominados, empezando por las clases más altas. Las cuales lo siguen utilizando y preservando como medio de reivindicación social.

\section{El significado de la pluma en la época colonial}

Dentro de este contexto el significado de la pluma en la época colonial sigue siendo el vínculo de los indígenas con sus dioses y con su concepción de las relaciones sociales políticas e ideológicas. Por medio del lenguaje pictográfico se pretende crear un vínculo entre su pasado y presente, pero al mismo tiempo, se vuelve una forma de expresión social que veladamente se desarrollaba en la época colonial y que se expresaba no solamente en la elaboración de cuadros religiosos que ya contenían su propia simbología. Si no también, sobrevive a partir de prendas y ornamentos que aunque eran menos espectaculares tenían la función de comunicar mensajes sociales y políticos. Y al mismo tiempo reflejaban la importancia de la identificación social. Conectándose con un proceso de elementos simbólicos entendidos por su propia comunidad. Era una manera de preservar lo único que la conquista no les había quitado: su identidad. Si bien las imágenes eran producidas para la iglesia y para la corona, dentro de la iconografía religiosa se expresaban códigos culturales dirigidos a la sociedad indígena. El uso de la pluma, la expresión de los colores, el tipo de aves, las técnicas utilizadas, los dibujos, eran parte de un significado ideológico propio de la sociedad prehispánica, los cuales tenían el mismo significado que en la época Mesoamericana y eran fruto de una cosmovisión que reflejaba una organización política y económica del trabajo, la cual, tenía un impacto en la ideología y el espacio social. La cosmovisión indígena y su reflejo político e ideológico se expresaron en los cristos y las vírgenes. Los códigos ideológicos quedaron reflejados en bellos cuadros, imágenes y relieves religiosos.

Aunque durante todo el proceso de la época colonial la pluma se vuelve menos accesible, la economía cambia las necesidades coloniales y las transforman. Las rutas y el mercado buscan satisfacer las necesidades de España y la evangelización hace más difícil las expresiones ideológicas. Solo queda reinventarse y buscar alternativas de comunicación más accesibles. El uso de las prendas y otros artículos ornamentales hacen más fácil la comunicación ideológica y social. La forma de garantizar la comunicación de los códigos sin cambiar el mensaje se da a partir de la herencia. De esa manera, el uso de la pluma era el correcto, los grupos nobles las heredaban de generación en generación, así preservaban los códigos de sus ancestros. Al usar estos objetos estaban implícitos los códigos de conducta, la importancia de la persona que los portaban y la forma de comportamiento de los demás sectores de la sociedad. La importancia de los amantecas no solo se debe a la trascendencia de su arte, si no a que forman parte de una expresión social e ideológica que, aunque a nivel cultural sufre un cambio, hace todo lo posible por sobrevivir.

Es importante entender estas expresiones como una forma de resistencia. Podríamos decir que el portar la pluma era una reivindicación necesaria después de tantas represalias hacia los elementos más 
representativos de su cultura. De alguna forma la aceptación de este arte por parte de la iglesia permite seguir conservando algunos códigos de comunicación ideológica de la sociedad. El arte se vuelve una expresión necesaria y reivindicativa para la sociedad dominada, como lo analiza Russo (1998: 67):

\begin{abstract}
«Fue justamente en ambientes como el hogar doméstico o en la actividad laboral donde la idolatría se reorganizó clandestinamente. Si nos detenemos sobre este particular, le hacemos porque a continuación se explicará por medio de episodios de sobrevivencia a través de los cuales la memoria indígena se reorganiza al interior de lugares como, por ejemplo, las diversas expresiones artísticas.»
\end{abstract}

\title{
VII. El uso de plumas en la vestimenta indígena
}

A nivel social se continuaba vistiendo a la clase noble, la cual se siguió distinguiendo de otros sectores de la población durante todo el periodo colonial como lo analiza Carrasco (1975: 181): «En el siglo XVI las diferencias sociales dentro de la sociedad indígena eran muy marcadas, y, a pesar de muchos cambios, la nobleza indígena sobrevivió hasta el fin de la colonia». Aunque los códigos de vestimenta habían cambiado para esta época, la adaptación a la nueva indumentaria se da rápido, pero el significado de ciertos objetos sigue siendo importante. Usando el análisis de Olko (2011) podemos observar que, aunque existe una adaptación a la moda europea por parte de la nobleza indígena, hay un apego a los elementos prehispánicos que eran relacionados con su propia identidad y que daban un mensaje de pertenencia social y cultural, así como, de estatus y poder, tales como la ropa y los ornamentos, los cuales seguían produciéndose con los mismos materiales, símbolos y la misma intención ideológica de la época prehispánica. Inclusive, se preservaba su nombre en su idioma de origen.

En este sentido el arte plumario tiene la función de seguir diferenciando y reflejando a los grupos nobles de la sociedad indígena de la época colonial y de alguna manera seguir distinguiendo el prestigio de los grupos más importantes de esta sociedad. La pluma, junto con otros materiales como el oro o piedras semipreciosas que eran usados en los ornamentos y ropa, comunicaban un proceso cosmogónico distinto que conectaba al indígena con su pasado (sus dioses, sus relaciones de producción, sus relaciones sociales, su entorno y cultura) y que transmitía respeto. Códigos importantes que formaban parte del lenguaje no verbal fortalecían de alguna manera una identidad que expresaba su sobrevivencia aun después de la conquista.

El lenguaje no verbal, que se expresa no solo en la indumentaria sino también en los ornamentos que porta el señor $\left(\right.$ cacique $^{10}$ ) va distinguir el nivel social y prestigio de todos los demás individuos de esta época. Además, aunque se habla de señores nobles con un puesto político determinado, el trabajo plumario también se sigue usando para distinguir a las mujeres que lo portan. Tal es el caso de las prendas femeninas conocidas como huipiles que reflejaban la importancia de las mujeres que los usaban. Un ejemplo es el huipil que todavía se conserva en el museo de antropología y que presuntamente pertenecía a la Malinche. Aunque esta prenda se populariza en el siglo XVI, y queda como la prenda de excelencia para las mujeres indígenas como lo analiza (SANDOVAL VILLEGAS 2009: 3):

«De tal suerte que los evangelizadores optaron por promover el atuendo femenino empleado en el centro México, realizando las adecuaciones pertinentes cuando fue necesario, para bacerlo entrar en el canon de honestidad requerido» (GAMEZ, 2004: 457).

10 «En la colonia se reconocían dos rangos de nobleza: los caciques, que eran los sucesores de los reyes o señores prehispánicos (tlatoque o teteuctin), y los principales (pipiltin en náhuatl; singular pilli) parientes de los caciques o sucesores de los pipiltin precortesianos» (Carrasco, 1975: 182). 
A finales del siglo XVI se comenta que en la antigüedad las indias: «como al presente se visten, aunque al presente -su traje- es más cumplido y honesto» (CARRILLO Y GARIEL, 1959: 46). Dentro de este contexto, la manera de distinguir a la nobleza de otros grupos sociales seguía siendo a través de los materiales que se usaban en su confección. Las plumas fueron imprescindibles para la distinción social. De esta forma los bordados utilizados representaban la importancia de las señoras que lo portaban y las distinguían de todas las demás.

\footnotetext{
«De tal suerte que la pluma, además de haberse empleado entera en el arte plumario tanto en cuadros de devoción, como cosida en vestuario, se usó también como una fibra textil estimada (Lechuga, 1991: 22). Prueba de ello es la mención de gran cantidad de buipiles de pluma que se anotan en los testamentos de la época. En los relatos de cronistas se advierte el impacto visual que el huipily la indumentaria de las indias en general les causó, debido básicamente al colorido y originalidad de los tejidos, por lo que en general los comentarios son favorables» (SANDOVAL VILLEGAS 2009: 7).
}

En este sentido, aunque el huipil se transforma a través de nuevos elementos de producción como la lana y la seda, el uso del arte textil plumario sigue siendo una referencia de prestigio ya que se vincula con los códigos de identidad propios de la cultura mesoamericana, siendo un punto de referencia de la posición social y de poder. Para la creación de la ropa y los ornamentos elaborados con plumas se usaban diferentes técnicas. Navarijo Ornelas (1998: 180) hace referencia a dos clases de técnicas en particular:

1. La obra con hilo y bramante, entre los que se encuentran los abanicos, brazaletes, divisas para la espalda, penachos, moscadores, estandartes y todo tipo de accesorios que colgaran (...)

2. La obra de mosaico la cual es una técnica que requiere de una gran habilidad y conocimiento de los colores para lograr combinaciones y tonos apropiados por medio de la superposición de plumas de diferente color.

Pero además hay una tercera técnica, analizada por Rivero Weber y Feest (2012: 54) los cuales citan a Sahagún, que es la técnica de hilado de pluma:

\begin{abstract}
«La que vende plumas biladas suele criar muchas aves de que pela plumas, y peladas envuélvelas con greda; y pela las plumas de arriba, y las que están debajo, que son muy blandas, como algodón, y bace todo lo siguiente; que bila pluma, bila parejo, bila atramuezos, bila mal torcido, bila bien torcido, tuerce la pluma, bila nequén con buso, con que bilan las mujeres otomitas, bila con torno la pluma pelada, y la torcida; hila también la pluma de pollos, e bila también la pluma de ánsares grandes, la pluma de ánades, la pluma de ánades del Perú, la pluma lavancos y la pluma de gallinas» (SAHAGÚN 1989: 576; SAHAGÚN 19501969,10: 92).
\end{abstract}

Sin embargo, el hilo torcido se utiliza hasta finales de la época colonial. Como lo analiza Héctor Meneses, director del Museo Textil de Oaxaca en una entrevista:

\footnotetext{
"Creemos que la técnica se dejó de utilizar en algún momento del siglo XVIII. Esto porque todas las piezas existentes están ubicadas entre la segunda mitad del siglo XVI y finales del XVII, a partir de alli ya no tenemos ejemplares físicos. Pero no solo eso, sino que los textiles emplumados y a no aparecen en pinturas, en descripciones, relatos ni en otros documentos, cosa que sí se observa durante los siglos XVI y XVII.» (NAVA 2017: 4)
} 

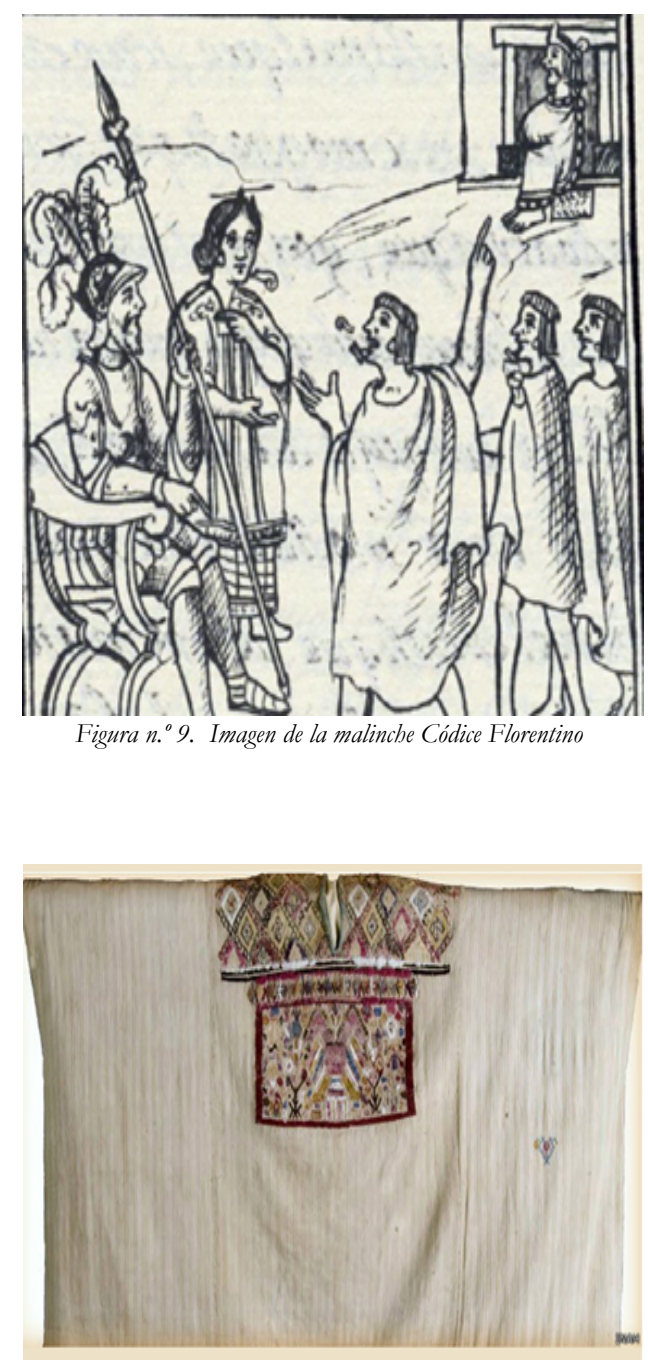

Figura n. ${ }^{\circ}$ 10. Huipil de la Malinche del Museo Nacional de Antropologia e Historia

Es interesante observar el rol de la mujer en la fabricación y uso de los huipiles, no hay que olvidar la importancia de esta en el proceso productivo de la ropa y en el caso de la utilización de la pluma. Ya hay referencias del trabajo de algunos grupos amantecas con sus mujeres, ellas compartían el oficio de hacer este trabajo en la época prehispánica como lo plantea Russo (1998: 72) al analizar a Sahagún. En los tiempos de la conquista eran los denominados Tecpan amanteca, que confeccionaban las vestimentas y ornamentos de Moctezuma, los Calpixcan amanteca, que trabajaban para el tesoro del tlatoani (vestidos con los cuales el tlatoani danzaba en honor de los dioses) y, en fin, estaban los Calla amanteca, los artistas que trabajaban en privado que, presumiblemente autogestionaban los frutos de su propia maestría vendiendo directamente en los mercados. Las mujeres participaban del trabajo de los propios maridos, por lo menos en esta fase. En la época colonial las mujeres continúan con las técnicas de trabajo textil con el fin de preservar su identidad. El textil se vuelve su herramienta de comunicación en donde expresan sus orígenes su estatus y su realidad. De una forma el tejido y los materiales utilizados para su elaboración se vuelven su expresión de identidad.

Además de los textiles también es interesante observar el uso de los ornamentos, los cuales permitían seguir utilizando los códigos de estatus y poder de manera menos vistosa, pero al mismo tiempo cumplían su función. Tomando como referencia a Olko (2011) en su estudio de los testamentos, la autora realza la 
importancia de la fabricación, el uso y el significado de muchos elementos ornamentales heredados a sus familiares. Lo interesante es que un gran número de estos efectos personales estaban hechos de pluma.

Según los testamentos de los cuales disponemos, varios gobernantes y nobles de la segunda mitad del siglo XVI poseían también mantas tilmatli decoradas con pluma según la costumbre prehispánica, plumería (mihuith), abanicos de plumas de quetzal quetzalehecacehuaztli, brazaletes macuextli, piedras cargadas de valor simbólico como chalchibuites y turquesas, así como plumas de quetzal, objetos que se encuentran en su totalidad asociados con la nobleza anterior a la conquista (Olko 2011: 462).

Al mismo tiempo, la autora analiza el uso de la terminología prehispánica para designar los artículos heredados. El uso tanto de la vestimenta como de los artículos ornamentales se daba en conmemoraciones específicas:

«Sin duda, el contexto principal mencionado por las fuentes disponibles en el cual sobrevivió el uso de los objetos del rango prehispánicos eran las fiestas y ceremonias, tanto religiosas, como seculares» (OLKO 2011: 463).

Es importante analizar el contexto de estas ceremonias ya que estos trajes y objetos distinguían a la nobleza indígena de la época, de las «castas». Los portadores de los ornamentos y las vestimentas eran objeto de respeto por parte de la población indígena que entendía los códigos políticos y sociales que estos elementos representaban. Estas fiestas continuaron el siglo XVII y XVIII. En el caso de la ropa, el lenguaje de los amantecas se transmitía de generación en generación a partir de testamentos, pero también a partir de las técnicas de elaboración, las cuales se fueron difundiendo por ciertos grupos ya no tan especializados en el arte plumario, como las mujeres, esta popularización del arte permitió seguir utilizando un producto sagrado e importante en la sociedad indígena, la pluma. Aunque los materiales de Europa fueron utilizándose de más en más por las mujeres de la nobleza, la pluma siguió utilizándose en los textiles y preservándose como parte de los elementos de prestigio utilizado no solamente por las nobles indígenas sino también por otras castas aunque en este caso el material eran más lujosos como lo analiza Sandoval Villegas (2009:11): Se ha establecido en varias ocasiones que las españolas usaron prendas de origen indígena (CURIEL, 2000: 96, GÁMEZ, 2004: 462). Esta aseveración tiene su base en los inventarios de bienes, en donde efectivamente se reiteran. Del análisis de las menciones de huipiles de españolas e indias se desprende que fueron por mucho más ricos las prendas de las blancas que las de las naturales.

Dentro de este contexto el significado de la pluma en la época colonial sigue siendo el vínculo de los indígenas con sus dioses y la expresión de las relaciones sociales políticas e ideológicas entre ellos. Por medio del lenguaje pictográfico se pretende crear un vínculo entre su pasado y presente, pero al mismo tiempo se vuelve una forma de expresión social que veladamente se desarrollaba en la época colonial y que se expresaba no solamente en la elaboración de cuadros religiosos que ya contenían su propia simbología. Sino que también, sobrevive a partir de prendas y ornamentos que, aunque eran menos espectaculares y tenían la función de comunicar mensajes sociales. Al mismo tiempo reflejaban la importancia de la identificación social, conectándose con un proceso de elementos simbólicos entendidos por su propia comunidad. Era una manera de preservar lo único que la conquista no les había quitado, su identidad cultural. Como hemos observado, en la época colonial, el arte plumario cambia, así como su entorno social, económico y ecológico. Los valores se transformaron y la pluma deja de tener ese sentido de divinidad, pero solo para las instituciones políticas e ideológicas de la Nueva España, no para los grupos indígenas dominados, empezando por las clases más altas, las cuales lo siguen utilizando y preservando como medio de reivindicación social. Las 
plumas les siguen dando ese reconocimiento e importancia dentro del entorno social y político en que vivían aun después de la conquista.

Aunque durante todo el proceso de transformación que se da en la época colonial la pluma se vuelve menos accesible, pues la economía cambia las necesidades coloniales se transforman, las rutas y el mercado buscan satisfacer las necesidades de España y la evangelización hace más difícil las expresiones ideológicas. Solamente queda reinventarse y buscar alternativas de comunicación más accesibles, el uso de las prendas y otros artículos ornamentales hacen más fácil la comunicación ideológica y social.

Como venimos analizando, para garantizar el fortalecimiento de los códigos de comunicación que llevaba implícito el arte plumario, el papel del amanteca y de la clase noble en la época colonial es fundamental; pues mientras el amanteca garantiza la comunicación del lenguaje pictográfico de acuerdo a los cánones ideológicos de la época prehispánica, la clase noble permite su difusión a nivel social, pues al mismo tiempo esto le permite tener su espacio de poder y reivindicar la ideología mesoamericana. La resistencia se da de manera sutil, con el objetivo de no perder su proceso de identidad cultural.

En este sentido, la forma de garantizar los códigos de comunicación sin cambiar el mensaje es a partir de la herencia. De esa manera, el uso de la pluma era el correcto, los grupos nobles las heredaban de generación en generación, así preservaban los códigos de sus ancestros y anticipaban la transformación social dada por la influencia europea. Al usar estos objetos estaban implícitos los códigos de conducta, así como la importancia de la persona que los portaban, pero principalmente, el usar la pluma junto con otros materiales propios de su identidad, formaba parte del reflejo de una historia que se negaba a morir.

En el caso de la ropa, la herencia garantizaba la subsistencia de su mensaje ya sea que la prenda se donara o se vendiera, como lo analiza Sandoval Villegas (2009: 5): «Entre las cuestiones más interesantes que se consignan en los testamentos de las mujeres indígenas, se encuentra el textil como herencia, ya sea para ser donado o vendido para obtener recursos y poder pagar las misas por el alma de la difunta, o bien, el propio entierro».

Esta popularización del arte permitió seguir utilizando un producto sagrado e importante en la sociedad indígena: la pluma. Aunque la influencia de los materiales de Europa fue creciente en las mujeres de la nobleza, la pluma siguió preservándose como parte de los elementos de prestigio utilizados no solamente por las nobles indígenas sino también por otras castas.

Dentro de este contexto la sobrevivencia del trabajo plumario se dio a partir de su utilización en la elaboración de prendas que permitieran guardar algunos de sus significados. Su uso en el proceso textil garantizó su popularización, la cual que era necesaria ya que después de la colonia, el orden político y social cambió y las relaciones con los grupos nobles indígenas se transformaron, pues ya no era necesario llegar a un acuerdo territorial y político. Lo que les pertenecía les fue arrebatado. De cierta manera la independencia no necesita al indígena, ya no hay necesidad del amanteca y llega la desaparición del arte plumario tal y como se le conoce y por ende también la de los amantecas. La manera en la que se preservó esta forma de comunicación simbólica y pictográfica además de los bellos retablos de la época colonial, se da a partir de la producción de huipiles y elementos ornamentales que todavía algunas etnias indígenas en México siguen utilizando. Entendiendo la producción textil y la utilización de elementos sagrados como la pluma, como una manera de comprender su origen y su relación con sus ancestros, además es una forma de no renunciar a su identidad cultural y a la comprensión de sus relaciones productivas e ideológicas, así como seguir expresando la importancia de sus orígenes y de sus dioses. 
El lenguaje pictográfico después de la independencia es más básico, pues las condiciones de sometimiento de los indígenas fueron más fuertes y sus recursos más precarios, pero sigue expresando su cosmovisión y la importancia de la identidad con sus ancestros, el lenguaje continúa como una forma de expresión social que lleva implícita las expresiones culturales que los distinguen de los otros grupos sociales. Aunque el significado y el tipo de pluma es distinto se siguen preservando algunas técnicas del arte plumario y rescatando otras.

Así encontramos que en la actualidad se siguen utilizando muchas de las técnicas ancestrales de producción de la ropa incluso la utilización de la pluma, como lo analiza Jiménez García (2009: 73) en su estudio de los huipiles de diversas regiones de México (principalmente región de Oaxaca y Chiapas):

«El algodón, la lana, las plumas, generalmente de gallina pero no únicamente, hilos bilados y teñidos con tintes naturales o anilinas, bilos comerciales de diversos colores, seda, incluso chaquira, son todos objeto de la delicada labor de estas artesanas, quienes no solo los combinan en una misma prenda, sino que utilizan técnicas ancestrales variadas al mismo tiempo que otras ajenas venidas de otras tierras, con pautas decorativas y referencias tanto autóctonas, como europeas, asimiladas durante los últimos quinientos años.»

La pluma se mantiene como parte de las expresiones culturales de los grupos indígenas, quienes siguen expresando su proceso ideológico y social, aunque se han transformado con el tiempo.

\section{Conclusión.}

La importancia del ave en la época prehispánica no solamente fue un objeto de comercio y de tributo, sino para las distintas culturas mesoamericanas, del norte y del occidente de México, las relacionaban con el sol, con la muerte, con el donador de la vida, para curaciones, etc. La consideraban parte de su cosmovisión y como protección. Por eso al ave la representaron en distintos objetos cerámicos y en murales, lo portaban los sacerdotes, los guerreros, las diosas y dioses relacionados con los amantecas y las mujeres nobles.

Las aves que utilizaron los amanteca provenían de varias áreas de Mesoamérica y del Norte. En cada uno de los objetos que realizaban para el arte plumario conocían la procedencia de esas aves, el significado de ellas y el color que querían resaltar. Para los indígenas amantecas no era un objeto de arte sino se relacionaba con sus dioses, con su ideología y con su naturaleza. El impacto de la conquista y después el proceso de sometimiento de la época colonial crea nuevas formas de comunicación no verbal por parte de los grupos sometidos, algunas motivadas por los evangelizadores y otras por el poder político, pero algunas otras creadas por la misma sociedad. Esta forma de comunicación hace que los elementos ideológicos de la cultura prehispánica subsistan gracias a las expresiones artísticas de diferentes grupos de entre los que se encuentran los amantecas que utilizaron sus conocimientos y su destreza para hacer sobrevivir códigos de comunicación culturales, en una sociedad completamente diferente, en la cual su arte formaba a ser parte, no solo; de una expresión religiosa reconocida en América y Europa, sino también se convierte en parte de la expresión política, ideológica y social de su grupo cultural.

Los grupos nobles forman parte del proceso de reivindicación cultural, gracias al poder otorgado por la corona, eso permite que puedan seguir utilizando artículos con una carga ideológica importante en la forma de prendas de vestir y ornamentos. La forma social de cómo subsisten las expresiones artísticas y el uso de la pluma posteriormente nos permiten observar una forma de resistencia, la cual sigue difundiendo un mensaje que no podía perderse, necesitaba existir, pues eso garantizaba la supervivencia de su identidad.

Es importante recalcar como conclusión que, si bien algunas técnicas de elaboración del arte plumario como el hilo torcido de pluma desaparecen en el siglo XIX, es en la actualidad cuando han surgido como una 
expresión de la identidad indígena, principalmente en la región de Oaxaca tomando como referencia el museo textil de Oaxaca, región del suroeste de México. Aunque desaparece el creador del arte plumario, el saber hacer permanece gracias a los códigos de comunicación transmitidos a través de la confección de ropa y ornamentos, los cuales permiten seguir entendiendo la pluma como algo sagrado. Para los grupos indígenas la indumentaria es una referencia de identidad, en donde se sigue preservando el lenguaje pictográfico con significados relativos a su historia y a sus costumbres. La pluma, por tanto, sigue siendo sagrada.

\section{REFERENCIAS BIBLIOGRÁFICAS}

ANALES DE CUAUHTITLÁN (1945). «Anales de Cuauhtitlán» En: Códice Chimalpopoca. (Traducción de Primo F. Velázquez). México: Imprenta Universitaria.

CÓDICE MATRITENSE DEL REAL PALACIO (1906). (Textos en Náhuatl de los indígenas informantes de Sahagún), ed. facs de Paso y Troncoso, vols. VI (2nda parte) y VII, Madrid, fototipia de Hauser y Manet, Fol. 175 v.

BRANIFF CORNEJO, B. (2009). «Comercio e interrelaciones entre Mesoamérica y la Gran Chichimeca»: 27-50. En: LONG TOWELL, J. y ATTOLINI LECÓN, A. (coord.), Caminos y mercados de México. México: Universidad Nacional Autónoma de México, Instituto de Investigaciones Históricas, Instituto Nacional de Antropología e Historia.

CARRASCO, P. (1975). «La transformación de la cultura indígena durante la colonia», Historia Mexicana, 25 (2): $175-203$.

DE LA TORRE VILLAR, E. (1998). «Manuel Carrera Stampa. Los gremios en la Nueva España»: 307-328. En: Lecturas históricas mexicanas, Tomo 5, $2^{\mathrm{a}}$ ed. México D. F.: Universidad Nacional Autónoma de México.

ESTRADA DE GERLERO, E. I. (1994). «La plumaria, expresión artística por excelencia»: 73-114, En: SABAU GARCÍA, M. L. (Dir.), México en el Mundo de las Colecciones de Arte: Nueva España 1, vol. 3. México: Secretaría de Relaciones Exteriores.

FLORESCANO, E. (1983). «La formación de los trabajadores en la época colonial, 1521-1750»: 9-124. En: FLORESCANO, E. et al. La clase obrera en la Historia de México. México D.F.: Siglo XXI editores.

FLORESCANO, E. (1997). «Sobre la naturaleza de los dioses de Mesoamérica», Estudios de cultura Nábuatl, (27): 4167.

FILLOY NADAL, L., SOLÍS OLGUÍN, F. y NAVARIJO, L. (2007). «Un excepcional mosaico de plumaria azteca: el Tapacáliz del Museo Nacional de Antropología», Estudios de cultura Nábuatl, (38): 85-100.

HERNÁNDEZ VACA, J. (2005). «La administración comunitaria del pueblo azteca». Estudios Políticos, (6): 113-144

JIMÉNEZ GARCÍA, A. (2009). Indígenas de Mundo Moderno. Aculturación de las etnias mexicanas ejemplificadas por medio de los textiles. Universidad de Palermo, Facultad de Diseño y Comunicación, Proyecto de Graduación. Trabajo final de grado.

Acceso el 8 de mayo de 2018

http://fido.palermo.edu/servicios_dyc/proyectograduacion/archivos/2071.41434

LEÓN-PORTILLA, M. (2006). La filosofía nábuatl estudiada en sus fuentes. México: Universidad Nacional Autónoma de México. 
LEÓN-PORTILLA, M. (1988). Los Antiguos Mexicanos a través de sus crónicas y cantares. México D.F.: Fondo de Cultura Económica.

MUÑOZ, S. (2006). «El Arte Plumario» y sus múltiples dimensiones de significación. La Misa de San Gregorio, Virreinato de la Nueva España 1539», Historia Crítica, (31):121-149.

NAVA, A. (2017). «El hilo emplumado, ciencia y arte se unen para recuperar el patrimonio», Agencia informativa de Consejo Nacional de Ciencia y Tecnología - Conacyt (en línea).

Acceso el 8 de mayo de 2018:

http://www.conacytprensa.mx/index.php/ciencia/arte/15940-hilo-emplumado-restauracion-arte

NAVARIJO ORNELAS, M. (2000). «Arte y ciencia a través de las imágenes de aves en la pintura mural prehispánica». Anales del Instituto de Investigación Estéticas, 22 (77): 5-32.

NAVARIJO ORNELAS, M. (1998). «Plumas...Tocados: una vieja historia de identidades perdidas»: 177-191. En: DE LA FUENTE, B. (coord.), La Pintura Mural Prehispánica en México: Bonampak. Vol. 2. Tomo I Estudios. México D.F.: Universidad Nacional Autónoma de México, Instituto de Investigaciones Estéticas.

OLKO, J. (2011). «Supervivencia de los objetos de rango prehispánicos entre la nobleza colonial nahua», Revista Española de Antropología Americana, 41 (2): 455-469.

OLKO, J. (2006). «Traje y atributos del poder en el mundo azteca: significados y funciones contextuales», Anales del Museo de América, 14, 2006: 61-88.

RIVERO WEBER, L. y FEEST, Ch. (2012). «La sombra de los dioses. El arte plumario en el México del siglo XVI»: 41-60. En: SABINE H., ALFONSO DE MARIA Y CAMPOS, RIVERO WEBER, L. FEEST, Ch., El Penacho del México Antiguo. Viena: Instituto Nacional de Antropología e Historia, Museum für Völker Kunde, ZKF Publishers.

ROMERO BLANCO, K. y MÉNDEZ D., C. (coord.) (2017). Mayas: el lenguaje de la belleza, Miradas Cruzadas. México D.F.: Museo Nacional de Antropología: 161-187.

RUSSO, A. (1998). «El encuentro de dos mundos artísticos en el arte plumario mexicano del Siglo XVI», Prohistoria, $2(2): 63-91$.

SAHAGÚN, Fray B. (1950-1982). Florentine Codex, General History of the Things of New Spain (1575-1585), 13 v., traducción, notas e ilustraciones de Ch. E. Dibble y A. J.O. Anderson, Santa Fe, The School of American Research/The Universityof Utah. Libro IX. Los Mercaderes: fos 56-67

SANDOVAL VILLEGAS, M. (2009). «El huipil precortesiano y novohispano transmutaciones simbólicas y estilísticas de una prenda indígena», Congreso Internacional Imagen Apariencia. Noviembre 19, 2008 - noviembre 21, 2008. Universidad de Murcia, Servicio de Publicaciones: (1-18).

VAILLANT, G. C., (1965). «El ritual»: 176-200. En: La Civilizacion Azteca. México: Fondo de Cultura Económica. 